\title{
EDITORIAL ¿POR QUÉ INVESTIGAR EN CIENCIAS DE LA SALUD?
}

Cómo citar: Morla E. ¿Por qué investigar en Ciencias de la Salud? cysa [Internet]. [citado 22 de febrero de 2022];6(1):3. Disponible en: https://revistas.intec.edu.do/index.php/cisa/article/view/2415

La respuesta a la pregunta que encabeza nuestro Editorial de este primer número de Ciencias y Salud, volumen 5, parecería sencilla y evidente: para dar atención a situaciones de salud individual o colectiva identificadas, no resueltas y planificar acciones preventivas de las mismas.

Al respecto, la Organización Panamericana de la Salud (OPS) señala que se debe investigar para:

- El bienestar de la humanidad.

- Incrementar el conocimiento y hacerlo accesible.

- Formular nuevas teorías o modificar las existentes.

- Solucionar problemas de la comunidad, medio ambiente e individuo,

- Mejorar la realidad existente.

- Crear nuevas tecnologías.

- Estimular para la actividad intelectual creadora.

Sin embargo, hay todo un abanico de situaciones que motivan a realizar alguna investigación. Por ejemplo, la necesidad de cumplir con un requisito académico de grado o postgrado: la exigencia de una investigación es muy frecuente. Aumentar el número de investigaciones y publicaciones para sustentar el currículo vitae e incrementar las posibilidades de adquirir posiciones en las instituciones de salud. Por esto, observamos frecuentes publicaciones de revisiones sistemáticas, que son investigaciones bibliográficas y que usualmente empleamos para enriquecer la pregunta de investigación y formar nuestro marco teórico.

Asimismo, hay quienes han identificado la investigación como una fuente de recursos económicos $\mathrm{y}$ han aprendido a vivir de esto.

Aunque la metodología para realizar una investigación de cualquier tipo está claramente definida, la motivación para realizar la misma es un elemento diverso, que estará siempre presente a lo largo de todo el proyecto de investigación.

\author{
Dr. Elbi Morla \\ Editor \\ ORCID: 0000-0001-6406-5709 \\ Correo-e: elbi.morla@intec.edu.do
}

